\title{
Study on Management of Cooperative Partnership between Normal University and Rural Kindergarten
}

\author{
Xiuning Yang \\ Department of Foreign Languages \\ College of Science and Technology of Gannan Normal University \\ Ganzhou, China 341000
}

\begin{abstract}
In the professional practice of pre-school education, corresponding establishment, maintenance, management activities and assessment should be carried out to really construct open, orderly, efficient and symbiotic partnership between normal university and rural kindergarten so as to ensure good operation of the partnership. Therefore, it's essential to redefine partnership and complete partnership maintenance, including selecting partners and signing cooperation agreement. Partnership maintenance should be guaranteed through effective communication, participant motivation, practical activities, resource integration and mechanism establishment. Besides, we should actively carry out effective evaluation activities in order to promote the healthy development of the partnership.
\end{abstract}

Keywords-normal university; rural kindergarten; cooperative partnership; management

\section{INTRODUCTION}

In America, the education-developed country, universities and kindergartens building cooperative relations is becoming the most important measure in recent American education reform. In our country, most normal universities have established cooperative relations with kindergartens. But there are few universities building cooperation with rural kindergartens. Under the ground of developing rural preschool education, higher normal universities building cooperative relations with rural kindergartens on co-exist principle is both good for improving the teaching situation of preschool and beneficial to the strengthen of practice capacity for preschool education major. In order to construct open, orderly, co-existent and high-effective cooperative relations, it's necessary to develop the corresponding establishment; assessment and other relation manage activities so that the cooperative relations can be ensured to run well.

\section{ESTABLISHMENT OF COOPERATIVE PARTNERSHIP}

To establish a cooperative partnership, at first, it is need to define the cooperative partnership from concept. Then begin the selection of cooperative partner. Finally, sign the

Fund project: Sponsored by the 2017 scientific \& technological research program of Educational Commission of Hubei Province: The Study on the Construction of Sport Competition Normalization Mechanism on the Campuses of Colleges and Universities in Hubei Province (Project number: B2017320). cooperation agreement to confirm the formal cooperative relation in law way.

\section{A. The Definition of Cooperative Partnership}

To establish and develop the effective cooperation, the higher normal universities need to define the relations of cooperative partners and insist on the principle of advanced concept. Therefore the higher normal universities should change the consume concept that they used to view the kindergarten only as site resource of novitiate and internship and they should establish the cooperative partner relation with rural kindergartens on the basis of co-existence. The cooperation here includes learning of practice principle, practice of child teaching, practice of teaching, research of young children and other multimensional cooperation, while cooperative partner relation means the developed, harmonious, healthy, multidirectional and continual connection of both parts in the partnership in these concrete practices.

After defining the cooperative relation, higher normal universities should base on this point to guide the selection of cooperation partner, the signing of cooperation agreement, the recognition of cooperation relation, the propelling of practice teaching and other work.

\section{B. Selection of Cooperative Partner}

The selection of cooperative partner matters in the whole event and it needs to be concise. The cooperation between higher normal universities and kindergartens touch on universities, rural kindergartens, local government, education authorities and other departments. High-quality cooperation has high demands for partner and relevant organization and members. These demands include: firstly, leaders and teachers of partner should have open mind, innovative ideology and can learn initiatively and positively to match up the education reform; secondly, partners have certain scale, in other words, they have their own special resources, accordant site and facility to satisfy students need for practice and reform; thirdly, partners and high normal universities have the target of co-existence and can benefit each other and coordinate with each other to develop; fourthly, partners and relevant organization along with members can support and cooperate with each other and supply corresponding condition. In the process of selecting 
partners, higher normal universities need to, according to the above requirements, combine their own condition and rural reality, have mutual benefit principle so as to treat it carefully and select concisely.

\section{The Signing of Cooperation Agreement}

To ensure that the collaboration activities develop in accordance with the law and regulations, colleges and universities should sign a cooperation agreement with the kindergartens so that both cooperation parties can act under the guidance of the agreement. The contents of the cooperation agreement mainly include the following parts: Firstly, the basic principle of collaboration, such as status, right, obligation, etc., including the division of authority and liability of partners and relevant organizations and personnel. Second are the goals and requirements of collaboration. The goals should consist of general targets, divisional targets. The requirements should emphasize complementary advantages, mutual learning and around symbiotic goal form learning community (all participants are the learners, consisting of administrative officials, university professors, kindergarten teachers, college students and children, etc.). Third are the modes of collaboration. The specific modes mainly include consultation, pairing, teamwork and comprehensive cooperation, etc. This paper discusses the object of comprehensive cooperation mode. Fourth is the security of collaboration. To guarantee the fulfillment of the agreement, stipulations on responsibility for breach of contract should be involved. Fifth is the extension of collaboration. In order to enrich cooperation contents, refine the obligation of both parties, enhance cooperation effects and reach the symbiotic goal, relevant stipulations on complementary agreement text need to be added. Only in this way can the cooperative partnership between normal universities and rural kindergartens be established formally.

\section{THE MAINTENANCE OF COOPERATIVE PARTNERSHIP}

After establishing the cooperative partnership, the maintenance work becomes necessary. Therefore, during the process of the maintenance, several key elements should be grasped.

\section{A. Communication: the Lubricant of Maintaining Relationship}

Cooperative partnership includes the internal organization relations, the inter-organization relations and the external inter-organization relations. It should be taken care of after established, while the communication is the lubricant of maintaining relationship. Effective communication is not only propitious to enhancing the mutual trust and respect of both parties, but also in favor of mobilizing enthusiasm of all participants to maintain partnership. Practice indicates that the specific cooperative goal, the reasonable cooperative mode, the wholesome cooperative mechanism, the explicit division of labor, the listen and reflection of the partners, the timely feedback and the patient statement tend to achieve effective communication. On the contrary, ineffective communication attributes to some major reasons: Firstly, the general cooperative objects, the defective cooperative mechanism, the indecorous cooperative method and the indistinct cooperative authority and responsibility. Secondly, it is the distinct personalities, the different standpoints, and the deficiency of tolerance and global view of the participants. Thirdly, it is the absence of communication skills in establishing trust and eliminating the divergence. Fourthly, participants are not willing to and not good at sharing the opinions about work or problems. Consequently, effective communication promote maintaining relationship work is actively launched as well as the ineffective communication should be avoided.

\section{B. Participant: the Organizational Basis of Maintained- relationship}

The participants of high-level colleges and universities and rural kindergarten major including the administrators of colleges, college teachers, undergraduates, the administrators of kindergarten, kindergarten teachers, infants, and regional relevant competent department executives. These participants together form the organizational basis of cooperative partnership. The quantities, quality, structure and receptivity of participants will have effect on the establishment and maintenance of cooperative partnership. Therefore, it is of great importance to follow these steps: Firstly, establish a cooperative organization consisting of both personnel, form a negotiable decision-making mechanism, conduct the cooperative activity uniformly, make sure the relationship accessible; Secondly, confirm the quantized proportion between both academic advisors and practical students reasonably, adjust the specialty construction of practical students reasonably, the group members should include special students of language, science, art, society, health and all kinds of fields. Thirdly, strengthen the practical teaching pattern cognition "cooperative partner" among mutual cooperative participants, learn the significances, goals, contents, patterns of implementing "cooperative partner. Fourthly, establish an evaluation and motivation mechanism, motivating all the participants' cooperative enthusiasm by various means, establish and maintain exoteric, well-organized, symbiotic, efficient cooperative partnership. Fifthly, high-level colleges and universities and rural kindergarten as the major part of cooperation should communicate with other relevant organizations and staff, try to gain their support, so as to create a favorable cooperative environment.

\section{Practice: the Key of Maintained-relationship}

The cooperative partnership between high-level colleges and universities and rural kindergarten originates from practice and forms and then develops in specific cooperative practical activity. Thus, holding fast to the specific cooperative practical activity is actually grasping the key of maintaining cooperative relationship. The contents of cooperative practical activity are as follows: Firstly, theory learning cooperation. Practical theory learning is the guarantee of science efficient practice. The primary forms are daily theory discussion, summer practical theory learning and so on. Besides, the high-level colleges and universities should provide faculty, textbook, place of practical theory 
learning. Secondly, teaching practice cooperation. The teaching practice of kindergarten is the most critical part, the patterns of cooperation including novitiate and internship, curricular and extracurricular. Besides, curricular cooperation includes kinds of concrete organization process, such as preparation before class, classroom execution, and after-class evaluation. Extracurricular mainly refers to the cooperation of outspread classroom fields, for instance, the collection of scientific curricular material, the selection of social course's contents and form. Thirdly, management practice cooperation. The future characters of preschool education major students are not only educators, but also administrators. It demands to strengthen the cooperation of management practice, so that students will acquaint with the whole management of kindergarten. Hence, the kindergarten should offer students management practice platforms. On the other hand, practicing students should participate in the kindergarten's management actively, and implement management jobs creatively. Fourth is education and scientific research cooperation. At present, scientific research is still a margin field in rural kindergarten. Therefore, the high-level colleges and universities should carry out a series of beneficial scientific research activities by means of daily practice experience summary, summer teaching and researching, research declaration and thesis writing. Making the administrators of kindergarten, teachers, practicing students fully aware of the significance of educational scientific research, improving the ability of educational scientific research, so as to improve the quality of rural infants' education and teaching in a deeper level.

\section{Resources: Material Guarantee for Maintaining Relationship}

The resources here refer to material resources, including a series of material guarantees that facilitate cooperation. They mainly refer to the followings: firstly, the experimental and training facilities inside university party are not only simulation facilities for college students but also material resources for rural preschool teachers and young children, including music classroom, dance classroom, training room of simulating activities, studio, hand making room, sensory integration training room; secondly, the place and facilities of rural kindergarten are not only the basis for organizing activities of rural kindergarten teachers and children, but also an important material platform for college student to go deep into rural practice; thirdly, they are the external resources that can be integrated between higher normal university and rural kindergartens, such as community resources, etc., which are also potential stock material resources that both sides of the cooperation should excavate and make full use of; fourthly, they are all kinds of practical materials that the cooperation between the two sides fight for through their own channels or use of cooperative relations, which is the incremental material resources benefiting the maintenance of the relationship. In order to excavate integrate and make good use of these material resources, it's necessary to arrange special personnel for unified planning and coordination to give play to all kinds of resources and ensure the maintenance of partnership.

\section{E. Institution: Institutional Guarantee for Relationship Maintenance}

It is an institutional guarantee to construct a series of mechanisms in order to maintain the cooperative partnership between higher normal university and kindergarten, which mainly includes target mechanism, content mechanism, process mechanism organization institution, policy guarantee and manage institution.

The target mechanism refers to the establishment and management of cooperation between the two sides of their respective goal and common goal, and association and integration of their own goal and common goal, specific objectives include a series of practical teaching objectives in higher normal colleges, educational goals and collaborative objectives in 33 rural kindergarten; the matching of the content mechanism and target mechanism refers to construction, organization and assessment of a series of cooperative activities' framework, which developed for goal, specifically including cooperative activities' formation mechanism, organization system and evaluation system; the process mechanism refers to a variety of institutional arrangements favorable cooperation in the process, mainly including the decision-making mechanism, communication mechanism, incentive mechanism, supervision mechanism, innovation mechanism; the organization institution refers to the cooperative organization system and its formation mechanism, operation rules and detailed rules; security policy refers to the policy and documents that the state, local and school made for benefiting cooperation, mainly including practice teaching of university and guiding advice about the developing of rural preschool education that the State Council, the Ministry of Education, local government and local education authorities carried out, such as "The outline of national medium and long term education reform and develop project(2010-2020)","Advice from education authorities for strengthening University Practice Education Job" and other files, along with the files formulated by universities and rural kindergartens for benefiting to support each other. The arrangement regime is the file formulated by universities and rural kindergartens individually or together to contribute to practice, teaching organization means to operation and arrangement measures, outline and other files, such as teaching outline in university and files for kindergarten to accept interns.

\section{EVALUATION OF THE PARTNERSHIP}

Positive and effective evaluation is conducive to promoting the development of cooperative partnership to foster high-quality preschool teachers and promote the quality of countryside, and even the total infant education. Therefore, corresponding evaluation institution and evaluation system need to be established, in order to make scientific and reasonable evaluation of the overall effect cooperation.

However, before the implement of a reasonable evaluation mechanism, the questions about "why, who, how to carry out evaluation" should be cleared, and adhere to the scientific evaluation in the evaluation practice of guiding 
ideology, set up the positive evaluation concept of mutual participation, qualitative and quantitative combination, the overall phase combination, on the basis of sufficient objective, key monitoring, the results are widely published, multidimensional mutual reflection, such as positive evaluation concept, only in this way can we form a relatively scientific, reasonable and effective evaluation mechanism. In addition, the rewarding mechanism which is based on the results of evaluation and the mutual benefits of both sides should be formed. And try to avoid the mismatching between the rewarding system and partner's cooperation, in order to arouse the enthusiasm of the participants to continue to work hard, to improve the effect of cooperation and to promote development of cooperation.

As for the construction of evaluation system, we should persist in the principle of diversification, for forming a scientific and complete cooperative practice teaching evaluation system; it is an important method to promote the quality of practice teaching steadily. The evaluation system is mainly divided into three dimensions.

The first is the student dimension. It primarily includes: colleges and universities are based on "double mark", The internal evaluation within a university of students' professional knowledge and ability through various ways, such as curriculum evaluation, skills display, competition activities and reflective diary; According to the evaluation scheme made by universities and kindergartens, evaluate the comprehensive performance of students in specific education and management practice about morality, ability, diligence and achievement in rural kindergarten, on the basis of daily performance and related records. Students evaluate themselves according to the evaluation criterion.

The second is the teacher dimension. It mainly refers to managers in college, kindergarten administrators and students who practice together to tutor students guidance and cooperation related dimensions of morality, ability, work, performance of comprehensive evaluation, and selfevaluation of teachers evaluation index based on their own, etc. Should be emphasized is that in the process of evaluating teachers, we should actively focus on teachers' consciousness and ability of initiative, continuous learning and educational research teaching. It is about the important aspects of teacher's professional development.

The third is the management dimension. It mainly refers to the cooperative management level, including: instructing teachers, practicing students, parents of young children and other people's comprehensive evaluation of the performance of the management of colleges and kindergartens. The university and the kindergarten managers evaluate their own self-evaluation and mutual evaluation according to the evaluation index.

\section{CONCLUSION}

"From practice, to practice; for practice, face to practice; accumulating practical experience and improving practical ability" is the only way to train high-qualified preschool teachers. Therefore, adhering to the practice is the inherent requirement of training professional talents in preschool education. The construction of cooperative partnership with rural kindergartens in rural areas, and in practice teaching is the need of the times. In order to build an open, orderly, symbiotic and efficient partnership, it is necessary to carry out the corresponding relationship. This is an important issue which is urgently needed to be solved in the practice teaching of preschool education.

\section{REFERENCES}

[1] Chen Qibiao. The Early Childhood Teacher Education Reform Based on University-Kindergarten Partnerships in the U.S.[J]. Jimei Univerisity Journal (Education Science Edition) 2009 (7): 6-10.

[2] Zeng Pingsheng, Zeng Huiying. Research of Practical Teaching Mode on Cooperative Partnership in Preschool Education in Normal University for Rural Areas[J]. Intelligence 2014 (10): 55-58.

[3] Ju Yucui. Analysis of University-School Partnerships--- based on school improvement[J]. Journal of the Chinese Society of Education, 2012 (4): 38-41.

[4] Du Yanhong. Construction and Implementation of the Practical Teaching System of Preschool Education[J]. Curriculum, Teaching Material and Method 2013 (2): 92-96. 